\title{
Emerging Roles of Dipeptidyl Peptidase-4 Inhibitors in Delaying the Progression of Type I Diabetes Mellitus
}

This article was published in the following Dove Press journal: Diabetes, Metabolic Syndrome and Obesity: Targets and Therapy

\author{
Jaquellyne Gurgel Penaforte- \\ Saboia $\mathbb{D}^{1,2}$ \\ Carlos Eduardo Barra Couri ${ }^{3}$ \\ Natasha Vasconcelos \\ Albuquerque ${ }^{1,4}$ \\ Vanessa Lauanna Lima Silva ${ }^{5}$ \\ Natália Bitar da Cunha \\ Olegario $^{1,2}$ \\ Virgínia Oliveira \\ Fernandes $(\mathbb{D})^{1,2,4}$ \\ Renan Magalhães \\ Montenegro Junior (D) 1,2,4 \\ 'Clinical Research Unit, Walter Cantidio \\ University Hospital, Federal University of \\ Ceará, Fortaleza, Brazil; ${ }^{2}$ Department of \\ Clinical Medicine, Federal University of \\ Ceará, Fortaleza, Brazil; ${ }^{3}$ Center for Cell- \\ Based Therapy, Ribeirão Preto Medical \\ School, University of São Paulo, São \\ Paulo, Brazil; ${ }^{4}$ Department of Community \\ Health, Federal University of Ceará, \\ Fortaleza, Brazil; ${ }^{5}$ Department of Clinical \\ Medicine, Hospital and Maternity Dra \\ Zilda Arns Neumann, Fortaleza, Brazil
}

\begin{abstract}
Type 1 diabetes mellitus (T1DM) results from the immune cell-mediated destruction of functional pancreatic $\beta$-cells. In the presymptomatic period, T1DM is characterized by the presence of two or more autoantibodies against the islet cells in patients without glycemic decompensation. Therapeutic strategies that can modify the autoimmune process could slow the progression of T1DM. Dipeptidyl peptidase-4 (DPP-4) or CD26, a multifunctional serine protease with a dual function (regulatory protease and binding protein), can modulate inflammation and immune cell-mediated $\beta$-cell destruction. CD26 is involved in T-cell costimulation, migration, memory development, thymic maturation, and emigration patterns. DPP-4 degrades the peptide hormones GLP-1 and GIP. In addition to regulating glucose metabolism, DPP-4 exerts anti-apoptotic, regenerative, and proliferative effects to promote $\beta$ cell mass expansion. GLP-1 receptor signaling may regulate murine lymphocyte proliferation and maintenance of peripheral regulatory T-cells. In patients with T1DM, the serum DPP-4 activity is upregulated. Several studies have suggested that the upregulated DPP-4 activity is correlated with T1DM pathophysiology. DPP-4, which is preferentially expressed on the Th1 surface, can promote the polarization of Th1 immunity, a prerequisite for T1DM development. CD26 inhibition can suppress T-cell proliferation and Th1 cytokine production and stimulate tumor growth factor beta-1 (TGF- $\beta 1$ ) secretion, which plays an important role in the regulation of autoimmunity in T1DM. Studies on humans or animal models of T1DM have suggested that DPP-4 inhibitors can improve $\beta$-cell function and attenuate autoimmunity in addition to decreasing insulin dependence. This review summarizes the emerging roles of DPP-4 inhibitors in potentially delaying the progression of T1DM.
\end{abstract}

Keywords: CD26, type 1 diabetes mellitus, autoimmunity, autoantibodies, therapeutic targets, prevention

\section{Introduction}

Type 1 diabetes mellitus (T1DM), a chronic disease, results from the immunemediated destruction of functional pancreatic $\beta$-cell mass. ${ }^{1}$ Insulitis is characterized by an inflammatory response that mainly involves CD8+ T-cells, CD68+ macrophages, CD4+ T-cells, CD20+ B lymphocytes, and CD138 plasma cells. The imbalance among the effector regulatory T-cells contributes to the development of insulitis. ${ }^{2}$ Consequently, insulitis leads to the enhanced production of cytokines, such as interferon-gamma (IFN- $\gamma$ ) and tumor necrosis factor-alpha (TNF $\alpha$ ) along with the activation of innate immunity and the secretion of other inflammatory factors, such as interleukin 1 beta (IL-1 $\beta$ ), induce $\beta$-cell death. ${ }^{3}$
Correspondence: Renan Magalhães Montenegro Junior

Federal University of Ceará, Rua Coronel

Nunes de Melo s/n, Fortaleza, 60430-270,

Ceará, Brazil

Tel +558533668600

Fax +5585 3366-8619

Email renanmmjr@gmail.com 
Insulitis was first reported in the $1960 \mathrm{~s} .{ }^{4}$ The correlation of T-cell abnormalities and some human leukocyte antigen alleles with juvenile-onset diabetes was identified in the 1970s. This led to the hypothesis that autoimmunity is the pathophysiological mechanism underlying the development of diabetes in a subgroup of patients. ${ }^{5}$

The identification of islet cell antibody (ICA) provided the first evidence for this hypothesis. ${ }^{6,7}$ Subsequently, the concept of a "prediabetic" stage was proposed according to which the production of antibodies precedes the onset of diabetes by several years. ${ }^{8,9}$ Various islet autoantibodies, such as insulin autoantibodies (IAA), glutamic acid decarboxylase antibodies (GADA) and islet autoantigens, such as tyrosine phosphatase-like insulinoma antigen (IA-2), and zinc transporter 8 (ZnT8) increase the risk of developing clinical type 1 diabetes. Previous studies have reported that most children with multiple islet autoantibodies develop clinical diabetes. ${ }^{10,11}$

The measurement of islet autoantibodies has enabled the prediction of T1DM risk. Clinical trials on the individuals in the prediabetic stage have enabled the identification and quantification of the risk of developing symptoms and the characterization of T1DM into well-defined stages. ${ }^{12}$ Stage 1 , a presymptomatic stage, is defined as autoimmunity against $\beta$-cells (two or more islet autoantibodies) with normoglycemia. The 5-year and 10-year risks of developing the symptomatic disease are approximately $44 \%$ and $70 \%$ in these patients, respectively. ${ }^{13}$ Stage 2 is a presymptomatic stage that is characterized by autoimmunity against $\beta$-cells and dysglycemia. The 5 -year risk of developing the symptomatic disease at this stage is approximately $75 \%$, while the lifetime risk approaches $100 \% .{ }^{14}$ Stage 3 is the onset of symptomatic disease. ${ }^{12}$

Recent findings on the cellular and molecular basis of immune-mediated diabetes progression and the characterization of T1DM stages have increased the number of trials that aim to intervene in the early stages of T1DM to prevent or delay progression to the symptomatic stage. ${ }^{15,16}$ Additionally, various therapeutic interventions that can potentially modulate the autoimmune process in T1DM have been examined. Dipeptidyl peptidase-4 (DPP4 or CD26) inhibitors (iDPP-4s), which are widely used to treat patients with type 2 diabetes mellitus (T2DM), are a potential therapeutic for T1DM. In addition to downregulating the degradation of incretin hormones, such as glucagon-like peptide-1 (GLP-1) and glucose-dependent insulinotropic polypeptide (GIP), ${ }^{17}$ DPP-4 is reported to modulate inflammation and immune-mediated $\beta$-cell destruction. ${ }^{18,19} \mathrm{CD} 26$ plays a central role in T-cell costimulation, migration, memory development, thymic maturation, and emigration patterns. ${ }^{20}$

T1DM, which is a progressive disease with a high incidence, is associated with high morbidity and mortality. However, the current therapeutic modality for T1DM, which lacks a curative therapy, is the administration of exogenous insulin. Various studies have demonstrated that the strategies to optimally manage diabetes, such as glycemic adjustment, adequate nutrition, and adherence to physical activity have a limited patient compliance. ${ }^{21,22}$

The use of drugs with the potential to prolong the presymptomatic period can reduce the long-term impact of T1DM. iDPP-4s are reported to exert immunomodulatory effects and can potentially delay the progression of T1DM. Thus, there is a need to evaluate the ability of iDPP-4s to prevent, delay, or cure T1DM.

\section{Immunomodulatory Effect of DPP-4 (CD26) in TIDM}

Type II transmembrane glycoprotein CD26 or DPP-4 is a multifunctional serine protease that functions as a regulatory protease and a binding protein. DPP- 4 is involved in the metabolism of peptide hormones and T-cell immune responses and T-cell activation and proliferation. Both soluble (DPP-4) and membrane-bound forms (CD26) are active in the dimer form. ${ }^{23,24}$

DPP-4 is a member of the prolyl oligopeptidase family, which comprises atypical serine proteinases that can hydrolyze the prolyl bond. ${ }^{25,26}$ The levels of DPP-4 are high in the seminal fluid, moderate in the plasma, and low in the cerebrospinal fluid. ${ }^{27}$ DPP-4 cleaves X-proline or $\mathrm{X}$-alanine dipeptides from the $\mathrm{N}$-terminus of polypeptides and consequently inactivates several chemokines, growth factors, neuropeptides, and peptide hormones. ${ }^{23,28}$

The peptide hormones GLP-1 and GIP contain an alanine at position 2, which is a substrate for DPP4-mediated degradation. ${ }^{29}$ GLP-1 and GIP, which are secreted from the intestine after ingestion of meals, are involved in glucose metabolism. Incretin hormones promote glucose-dependent insulin secretion from the pancreatic $\beta$-cells and suppress excessive glucagon secretion from the $\alpha$-cells. Additionally, animal and in vitro studies have revealed that GLP-1 and GIP exert anti-apoptotic, regenerative, and proliferative effects to promote $\beta$-cell mass expansion. ${ }^{30}$ Hadjiyanni et al demonstrated that GLP-1 receptor (GLP-1R) signaling may regulate murine 
lymphocyte proliferation and maintain the pool of peripheral regulatory T-cells. ${ }^{31}$ The inhibition of DPP-4 activity can downregulate the degradation of GLP-1 and GIP and consequently enhance their therapeutic efficacy. ${ }^{32}$

The enhanced activity of DPP-4 did not result in systemic immune activation. However, enhanced DPP-4 activity was associated with hepatic T-cell activation under various clinical conditions, such as patients with human immunodeficiency virus and hepatitis $\mathrm{C}$ virus coinfections exhibiting hepatotoxicity after highly active antiretroviral therapy. ${ }^{33}$ Previous studies have reported that the serum DPP-4 levels were upregulated in some autoimmune diseases, such as Graves' disease, Hashimoto thyroiditis, multiple sclerosis, and primary biliary cholangitis. In contrast, the serum DPP-4 levels were downregulated in systemic lupus erythematosus and antineutrophil cytoplasmic antibody-associated vasculitis. ${ }^{34,35}$

One study evaluated the serum DPP-4 activity in 48 patients with T1DM (mean T1DM duration: $13.4 \pm 9.76$ years) and 50 healthy individuals. The fasting serum DPP4 activity was upregulated in patients with T1DM independent of the presence of the ICA and GADA. ${ }^{36}$ Another study involving 76 young Japanese patients with T1DM and 22 healthy volunteers demonstrated that the serum DPP-4 activity was significantly upregulated in patients with T1DM. ${ }^{37}$ Iwabuchi et al examining 43 Japanese children with T1DM and 26 age- and sex-matched healthy volunteers also reported that DPP-4 activity was significantly upregulated in the T1DM group without correlation with glycated hemoglobin (HbA1c), blood glucose, GADA status, or diabetes duration, but with an inverse correlation with insulin sensitivity. ${ }^{38}$

Duvnjak et al compared the serum DPP-4 activity within 19 latent autoimmune diabetes of the adult (LADA), 21 T1DM, 26 T2DM and 13 healthy controls patients, demonstrating that individuals with LADA express higher DPP-4 activity than the ones with T1DM and T2DM (mean duration of diabetes $20.3 \pm 11.3$ years for 3 groups). ${ }^{39}$ Once the strong correlation among serum DPP-4 activity, anthropometric parameters and insulin resistance (IR) has been showed, ${ }^{36,38}$ the higher DPP-4 activity in LADA patients could be justified by their significantly higher waist circumference than T1DM patients and also by a probably higher IR (represented by a higher insulin dose) than T2DM patients. ${ }^{39}$

The mechanisms underlying the upregulated DPP-4 activity in T1DM and LADA have not been elucidated. Some studies have suggested that hyperglycemia can upregulate DPP-4 activity. Sustained hyperglycemia is reported to enhance the levels of advanced glycation end products (AGEs), which consequently affect the release of DPP-4 from the cell surface and upregulate DPP-4 in T1DM $^{40}$ In patients with T2DM, the serum levels of DPP-4 are correlated with those of AGEs. ${ }^{41}$ It was shown earlier that iDPP-4s suppress atherosclerotic vascular injury in diabetic animals by inhibiting the deleterious effects of AGEs. ${ }^{40,42-45}$ The use of teneligliptin in T1DM patients as well as in streptozotocin-induced T1DM mice may inhibit foam cell formation and oxidized low-density lipoprotein (ox-LDL) uptake of macrophages via suppression of CD36 and acyl-coenzyme A: cholesterol acyltransferase-1 (ACAT-1) gene expression. Thus, the harmful effects of AGEs are attenuated. In mice, teneligliptin reduced all the damaging effects of AGEs in THP-1 cells and macrophages. ${ }^{46}$ The exposure of human glomerular endothelial cells to enhanced glucose level resulted in the upregulation of messenger RNA expression and activity of DPP- $4 .{ }^{47}$ Similar findings have been reported in the human hepatocyte line HepG2 cells. ${ }^{48}$

However, some studies have suggested that the upregulated activity of DPP-4 is associated with T1DM pathophysiology as it is involved in T-cell immune responses. DPP-4 can modulate in vitro T-cell proliferation and enhance T-cell transendothelial migration. ${ }^{23,24}$ The members of the chemokine family are the common DPP-4 substrates for immune function.

CD4+ T-cells can be subclassified into T-helper 1 (Th1) and T-helper 2 (Th2) cells. The Th1 cells predominantly produce IL- 2 , IFN- $\gamma$, and TNF- $\beta$. The Th2 cells secrete cytokines, IL-4, IL-5, and IL-10. ${ }^{49}$ A consequence of DPP-4-mediated cleavage of chemokines inhibits the stimulation of Th2 immune responses. Additionally, DPP-4, which is predominantly expressed in the Th1 cells, can shift the chemokine activity toward the stimulation and attraction of Th1 cells. DPP-4 cleaves regulated on activation, normal T-cell expressed and secreted, eotaxin, monocyte-derived chemokine, stromalderived factor (SDF)-1 $\alpha$, and SDF-1 $\beta$. The cleavage products of these chemokines trigger Th1-specific chemokine receptors but not Th2-specific chemokine receptors. ${ }^{50,51} \mathrm{In}$ contrast, the inhibition of DPP-4 increases Th2 cytokine secretion. $^{52}$

Studies on the humans and diabetic animal models have reported that the functional polarization of Th lymphocyte subsets is a potential risk factor for T1DM. The impairment of Th2 function and Th1 immunity are the 
prerequisite for disease development. ${ }^{53,54}$ Studies on children with a recent diagnosis of T1DM and high-risk (ICA $\geq 20$ ) first-degree relatives of patients with T1DM have revealed that the cellular responses against the islet cell antigen glutamic acid decarboxylase 65 involve the Th1 phenotype ${ }^{55,56}$ Similar results have been reported in the diabetic animal models. Polarized Th function is associated with disease development in non-obese diabetic (NOD) mice and BioBreeding rats. ${ }^{53,57}$

The ability of DPP-4 to modulate the activities of neuropeptides, such as substance $\mathrm{P}$, neuropeptide $\mathrm{Y}$, and endomorphin-2 may contribute to the regulation of interactions between the nervous and immune systems. ${ }^{27}$

Membrane-bound CD26 is expressed in various cells and tissues, such as the T-cells, B-cells, and natural killer cells, melanocytes, epithelia of the renal tubule, endothelial cells, and colonic mucosa. CD26 is critical for the T-cell immune responses as it can modulate T-cell proliferation in vitro and deliver a costimulatory signal for T-cell activation. The resting lymphocytes exhibit minimal levels of CD26. In contrast, the activation of lymphocytes upregulates the expression of CD26. The stimulated T-cells exhibit enhanced expression levels of CD26, which were equivalent to those in the epithelial cells. ${ }^{23,24}$ Moreover, the depletion of CD26, a thymic maturation marker, affects the lymphocyte composition, memory T-cell generation, and thymic emigration patterns. ${ }^{58}$

CD26, which serves as a receptor for adenosine deaminase (ADA) on the T-cell surface, ${ }^{59}$ can modulate the concentration of local extracellular and intracellular ADA levels. ${ }^{24,60}$ The expression levels of ADA inversely regulate cellular proliferation and apoptosis. The binding of ADA to CD26/DPP-4 on the surface of T-cells promotes IL-2 production and secretion. ${ }^{61,62}$

In the antigen-presenting cells, caveolin-1 ligates the CD26 dimers on the T-cell surface, which results in the recruitment of lipid rafts to the plasma membrane and CARMA1 to the cytosolic portion of CD26. This leads to the activation of nuclear factor- $\mathrm{KB}, \mathrm{T}-\mathrm{cell}$ proliferation, and IL-2 production. ${ }^{63}$ Furthermore, CD26, regulates adhesion, cytoplasmic dissemination, and migration of T-cells in the intra-plasma membrane by promoting the interaction of chemokine receptors with thrombospondin-1 and CD91. ${ }^{64}$

The inhibition of CD26 is reported to suppress T-cell proliferation and Th1 cytokine production and stimulate tumor growth factor beta-1 (TGF- $\beta 1$ ) secretion, which plays an important role in the regulation of autoimmunity in T1DM. ${ }^{65}$ TGF- $\beta 1$ mediates the function of regulatory
T-cells and regulates the expansion of Foxp3-expressing CD4+ CD25+ regulatory T-cells. ${ }^{66}$ Regulatory T-cells can suppress effector T-cell migration, accumulation, and proliferation in draining lymph nodes and inflamed tissues. Additionally, regulatory T-cells are involved in the maintenance of self-tolerance and the prevention of autoimmune diseases. ${ }^{67}$ The CD26-deficient rats are reported to exhibit an enhanced number of regulatory T-cells and a decreased number of memory T-cells. ${ }^{58}$

The upregulation of CD4+ CD25+ Foxp3 regulatory T-cells in the pancreatic lymph nodes ameliorated autoimmunity in NOD mice. Cyclophosphamide-induced exacerbation of diabetes in NOD mice was associated with a decreased pool of CD4+ CD25+ Foxp3 regulatory T-cells. ${ }^{68,69}$

There are contradictory findings on CD26 expression in T1DM. A trial involving 48 patients with T1DM and 50 healthy individuals revealed an upregulated serum DPP-4 activity and a significantly downregulated expression of lymphocyte membrane-bound CD26 without any correlation between serum DPP-4 enzymatic activity and CD26 expression in patients with T1DM. ${ }^{37}$ This altered activity of serum DPP-4 and expression of CD26 can be attributed to the secondary change in the entero-insular axis and might be a novel part of the T-lymphocyte regulatory dysfunction observed in T1DM. Caveolin-1 can be a potential downstream target in CD26 signaling and T-cell co-stimulation. ${ }^{63,70}$

Matteucci et al analyzed the proportions of naïve $(\mathrm{N})$, central memory $(\mathrm{CM})$, effector memory, and terminally differentiated effector memory (TEMRA) subsets among CD4+ and CD8+ T-cells expressing CD26 in the peripheral blood of 55 patients with T1DM and 20 healthy volunteers. The authors demonstrated that the T1DM group was associated with decreased proportions and absolute numbers of $\mathrm{CM}$ and $\mathrm{N}$ cells and increased proportions and absolute numbers of TEMRA cells. The ability of accumulated TEMRA cells in patients with T1DM to elicit life-long upon stimulation by protracted antigen exposure (such as viruses or residual self-antigens) or a homeostatic defect in the regulation/contraction of immune responses is not clear. ${ }^{20}$

\section{Experimental and Clinical Studies with iDPP-4}

Several clinical trials have evaluated the safety and efficacy of iDPP-4 in T1DM. ${ }^{71,72}$ In vitro, human, and animal 
studies have suggested that iDPP-4s could enhance $\beta$-cell function and attenuate autoimmunity in T1DM. In 2010, we investigated the ability of iDPP-4 to alleviate newonset diabetes in NOD mice, modulate the inflammatory response, and stimulate $\beta$-cell regeneration. After the diagnosis of new-onset diabetes (non-fasting blood glucose level $>250 \mathrm{mg} / \mathrm{dL}$ on at least two consecutive measurements), the mice were orally treated with iDPP-4 for 2,4 , or 6 weeks along with insulin if the blood glucose level was $>200 \mathrm{mg} / \mathrm{dL}$. Compared with that in the insulin treatment group, diabetes was mitigated (blood glucose levels consistently remaining $<200 \mathrm{mg} / \mathrm{dL}$ ) in 57,74 , and $73 \%$ of mice after 2, 4, and 6 weeks of treatment with iDPP-4, respectively. However, long-term remission could not be induced. In NOD mice treated with iDPP-4 for 2 weeks, the mean blood glucose level increased in most mice after discontinuing iDPP-4. Treatment with iDPP-4 for 4 and 6 weeks markedly mitigated new-onset diabetes but could not induce long-term remission. The symptoms of diabetes gradually reemerged after stopping treatment. The disease relapse after stopping the treatment is associated with the reduction in the regulatory T-cell pool. The analysis of rats in remission revealed a marked reduction in insulitis and an enhanced proportion of CD4+ CD25+ Foxp3+ regulatory T-cells among the total CD4+ T-cells. The plasma TGF- $\beta 1$ and GLP- 1 levels were significantly upregulated in the rats in remission. Additionally, the insulin content and the number of insulin and bromodeoxyuridine-positive cells (representing replicated B-cells) in the pancreas significantly increased in the rats in remission. These findings suggest that immune regulation plays a critical role in alleviating new-onset diabetes in iDPP-4-treated NOD mice. $^{18}$

Another study analyzed the effect of sitagliptin treatment for 30 and 90 days in a streptozotocin-induced T1DM experimental animal model. Diabetic mice treated with iDPP-4 exhibited significantly downregulated blood glucose levels, attenuated glycemic response to oral glucose tolerance test, and significantly upregulated GLP-1 serum levels. After 90 days of treatment, iDPP-4-treated diabetic animals exhibited significantly upregulated serum insulin concentrations. Additionally, some mice exhibited a non-significant increase in the number of small pancreatic islets. Furthermore, iDPP-4-treated mice exhibited a decreased proportion of $\mathrm{CD} 4+\mathrm{CD} 26+\mathrm{T}$-cells and an increased proportion of CD4+CD25hiFoxp3 + T-cells in the spleen. iDPP-4 modulated the pancreatic inflammatory profile. Pancreatic lymph nodes from iDPP-4-treated mice exhibited a decreased proportion of CD11b+ cells and decreased levels of inflammatory cytokines in the pancreas, especially IFN $-\gamma^{73}$

A previous study reported that two young women with T1DM achieved clinical remission for 4 years after treatment with sitagliptin and vitamin D3. One patient used the oral drugs for approximately 1 month after T1DM diagnosis, while the second patient used them after 10 months. In addition to clinical remission, the two patients exhibited stable C-peptide (CP) levels during this period with early and significantly downregulated GADA levels. However, both patients had factors associated with better outcomes in immunological intervention studies, such as the absence of ketoacidosis at diagnosis, age of more than 14 years, and positive fasting CP levels at the onset of T1DM. ${ }^{74}$ Similarly, Lima-Martínez et al described a case of a 19year-old male who started using sitagliptin $(100 \mathrm{mg} /$ day $)$ three days after T1DM diagnosis. The patient exhibited ketoacidosis at the time of T1DM diagnosis and entered remission eight weeks after diagnosis. Additionally, the patient was in remission until the time of the publication (15 months of sitagliptin treatment). ${ }^{75}$

In 2009, a study reported two patients who remained insulin-free for 47 and 43 months after treatment with autologous non-myeloablative hematopoietic stem cell transplants and returned to insulin use. After 4 and 2 months of insulin resumption, $100 \mathrm{mg} /$ day sitagliptin was prescribed. The two patients were insulin-free after 2 months and 1 month of using iDPP-4 for another 5 and 6 months, respectively. Additionally, the patients exhibited upregulated levels of $\mathrm{CP}^{76}$

Recently, a trial conducted by Kumar et al randomized 18 newly diagnosed T1DM cases into the following three groups: group 1, treated with insulin; group 2, treated with insulin and exenatide (5 mg subcutaneously administered twice daily for one month and subsequently $10 \mathrm{mg}$ twice daily); group 3, treated with insulin and sitagliptin (100 mg daily). The insulin requirement of all groups decreased after 12 months of treatment. Compared with that in group 1, the decrease in insulin requirement was higher in groups 2 and $3 .^{77}$

Another study enrolled 20 adults with long-term T1DM and treated them with sitagliptin (100 mg/day), or placebo along with insulin for 4 weeks and then the subjects were crossed over. Sitagliptin significantly improved the parameters of overall glucose control, including postprandial and 24-h glucose levels, and significantly decreased prandial insulin requirements. ${ }^{78}$ 
A meta-analysis assessed the therapeutic effects of iDPP-4 on T1DM and included patients with both newly diagnosed and long-term disease. The use of iDPP-4 was associated with a reduction in the daily dose of insulin (units/day). The medication was well tolerated. Among the six studies included in the analysis, two patients exhibited self-limited nausea, one patient reported a rash, and one patient had abdominal pain. None of the patients in the six studies developed ketoacidosis. Additionally, the incidence of severe hypoglycemia was not affected. ${ }^{79}$

Another meta-analysis published in 2018 including 253 participants (only $120 \mathrm{CP}$ positive patients) from 5 randomized controlled trials (RCTs) revealed that the addition of iDPP-4 to insulin therapy resulted in a greater, but not significant, reduction in HbA1c levels. A small decrease in postprandial glucose and insulin dose were also noted. Regarding the function of $\beta$-cell, from 120 patients with positive $\mathrm{CP}$, the increase in fasting $\mathrm{CP}$ (FCP) level could not be showed in the group treated with iDPP-4. However, it is important to note that none of the 5 RCTs have assessed immunological indicators. ${ }^{80}$

Zhao et al evaluated the use of sitagliptin ( $100 \mathrm{mg} /$ day $)$ in patients with a recent diagnosis (three years or less) of LADA and exhibiting FCP level of $\geq 200 \mathrm{pmol} / \mathrm{L}$ or a 2 -h postprandial CP level of $\geq 400 \mathrm{pmol} / \mathrm{L}$. Thirty patients were randomized into groups treated with insulin with or without sitagliptin $100 \mathrm{mg}$ daily for 12 months. In the sitagliptin group, the 2-h postprandial CP and delta CP levels after 12 months were similar to those at the baseline. However, the levels of 2-h post-prandial CP and delta $\mathrm{CP}$ were significantly downregulated in the insulin group. After 12 months of treatment, the GADA titers, insulin dosage, fasting glucose, 2-hour postprandial glucose, and $\mathrm{HbA1c}$ levels were not significantly different from that at baseline and after 3, 6, 9, and 12 months of treatment. ${ }^{19}$

Another study comparatively analyzed CP levels in patients with LADA who were treated with linagliptin or glimepiride. Linagliptin preserved $\beta$-cell function in patients with LADA during the 2-year study period. The FCP levels increased at weeks 28, 52, and 104 when compared with those at baseline in linagliptintreated patients but decreased in glimepiride-treated patients. Mean HbAlc levels was similar in both groups. ${ }^{81}$ These results suggest that iDPP-4 may have attenuated the rate of decline in $\mathrm{CP}$ levels in patients with LADA. These findings also indicated that changes in glucose levels may affect $\beta$-cell function. ${ }^{82}$ However, glycemic control was similar between groups in both studies. Therefore, the loss of $\beta$-cell secretion in iDPP4-treated patients was not dependent on the glucose levels and the decreased glucotoxicity was not responsible for $\beta$-cell preservation.

Regarding general adverse events, iDPP-4 are generally well tolerated. Controversial data has historically associated the use of iDPP-4 with an increased risk of pancreatitis and pancreatic cancer. ${ }^{83-87}$ However, an up to date meta-analysis including 165 trials performed on T2DM, with duration $\geq 24$ weeks, revealed no association between the use of iDPP-4 and an increased risk of pancreatitis or pancreatic cancer without significant differences across individual molecules in the class. ${ }^{88}$ Another meta-analysis that included only T1DM showed no serious side effects clearly related to the iDPP-4 including ketoacidosis and pancreatitis. ${ }^{80}$ Furthermore, several metanalyses have shown no differences between iDPP-4 and placebo concerning major cardiovascular events. ${ }^{89-92}$

\section{Conclusion}

T1DM, as well as LADA, which are progressive diseases with a high incidence, are associated with high morbidity and mortality. The major therapeutic modality for both, which has no curative therapy, is the administration of exogenous insulin. T1DM and LADA can be effectively managed using iDPP-4s. To the best of our knowledge, this is the first study to review the pathophysiological mechanism underlying the rational use of iDPP-4s, which have the potential to slow the progression of T1DM and LADA. However, this study was limited to a literature review. Among the reviewed studies, some studies had small sample sizes with inadequate reporting of raw participant data and/or standard deviations. Additionally, this review included studies that used different iDPP-4s, dosages, and treatment durations (ranging from weeks to months). However, this study reviewed interesting data that should be considered to design therapeutic strategies for both T1DM and LADA to prevent or delay the onset of symptoms.

\section{Author Contributions}

All authors made substantial contributions to conception and design; acquisition, analysis and interpretation of data; took part in drafting the article and revising it critically for important intellectual content; agreed to submit to the current journal; gave final approval of the version to be published; and agree to be accountable for all aspects of the work. 


\section{Funding}

There is no funding to report.

\section{Disclosure}

The authors report no conflicts of interest for this work.

\section{References}

1. Atkinson MA, Eisenbarth GS, Michels AW. Type 1 diabetes. Lancet. 2014;383(9911):69-82. doi:10.1016/S0140-6736(13)60591-7

2. Willcox A, Richardson SJ, Bone AJ, Foulis AK, Morgan NG. Analysis of islet inflammation in human type 1 diabetes. Clin Exp Immunol. 2009;155(2):173-181. doi:10.1111/j.1365-2249.2008.038 60. $\mathrm{x}$

3. Bluestone JA, Herold K, Eisenbarth G. Genetics, pathogenesis and clinical interventions in type 1 diabetes. Nature. 2010;464 (7293):1293-1300. doi:10.1038/nature08933

4. Gepts W. Pathologic anatomy of the pancreas in juvenile diabetes mellitus. Diabetes. 1965;14(10):619-633. doi:10.2337/diab.14.10.619

5. Strosberg JM, Harris ED Jr. Letter: HL-A genotypes and diabetes. Lancet. 1974;2(7890):1212. doi:10.1016/S0140-6736(74)90857-5

6. Bottazzo GF, Florin-Christensen A, Doniach D. Islet-cell antibodies in diabetes mellitus with autoimmune polyendocrine deficiencies. Lancet. 1974;2(7892):1279-1283. doi:10.1016/S0140-6736(74)901 40-8

7. MacCuish AC, Irvine WJ, Barnes EW, Duncan LJ. Antibodies to pancreatic islet cells in insulin-dependent diabetics with coexisten autoimmune disease. Lancet. 1974;2(7896):1529-1531. doi:10.1016/ S0140-6736(74)90281-5

8. Irvine WJ, Gray RS, McCallum CJ. Pancreatic islet-cell antibody as a marker for asymptomatic and latent diabetes and prediabetes. Lancet 1976;2(7995):1097-1102. doi:10.1016/S0140-6736(76)91084-9

9. Lendrum R, Nelson PG, Pyke DA, Walker G, Gamble DR. Islet-cell, thyroid, and gastric autoantibodies in diabetic identical twins. $\mathrm{Br}$ Med J. 1976;1(6009):553-555. doi:10.1136/bmj.1.6009.553

10. Watkins RA, Evans-Molina C, Blum JS, DiMeglio LA. Established and emerging biomarkers for the prediction of type 1 diabetes: a systematic review. Transl Res. 2014;164(2):110-121. doi:10.1016/ j.trsl.2014.02.004

11. Bonifacio E, Achenbach P. Birth and coming of age of islet autoantibodies. Clin Exp Immunol. 2019;198(3):294-305. doi:10.11 11/cei. 13360

12. Insel RA, Dunne JL, Atkinson MA, et al. Staging presymptomatic type 1 diabetes: a scientific statement of JDRF, the endocrine society, and the American diabetes association. Diabetes Care. 2015;38 (10):1964-1974. doi:10.2337/dc15-1419

13. Ziegler AG, Rewers M, Simell O, et al. Seroconversion to multiple islet autoantibodies and risk of progression to diabetes in children JAMA. 2013;309(23):2473-2479. doi:10.1001/jama.2013.6285

14. Krischer JP. Type 1 diabetes trialnet study group. The use of intermediate endpoints in the design of type 1 diabetes prevention trials. Diabetologia. 2013;56(9):1919-1924. doi:10.1007/s00125-013-2960-7

15. Association AD. Effects of oral insulin in relatives of patients with type 1 diabetes: the diabetes prevention trial-type 1. Diabetes Care. 2005;28(5):1068-1076. doi:10.2337/diacare.28.5.1068

16. Vandemeulebroucke E, Gorus FK, Decochez K, et al. Insulin treatment in IA-2A-positive relatives of type 1 diabetic patients. Diabetes Metab. 2009;35(4):319-327. doi:10.1016/j.diabet.2009.02.005

17. Holst JJ. The physiology of glucagon-like peptide 1. Physiol Rev. 2007;87(4):1409-1439. doi:10.1152/physrev.00034.2006

18. Tian L, Gao J, Hao J, et al. Reversal of new-onset diabetes through modulating inflammation and stimulating $\beta$-cell replication in nonobese diabetic mice by a dipeptidyl peptidase IV inhibitor. Endocrinology. 2010;151(7):3049-3060. doi:10.1210/en.2010-0068
19. Zhao Y, Yang L, Xiang Y, et al. Dipeptidyl peptidase 4 inhibitor sitagliptin maintains $\beta$-cell function in patients with recent-onset latent autoimmune diabetes in adults: one year prospective study. J Clin Endocrinol Metab. 2014;99(5):E876-80. doi:10.1210/jc.20 13-3633

20. Matteucci E, Ghimenti M, Di Beo S, Giampietro O. Altered proportions of naive, central memory and terminally differentiated central memory subsets among CD4+ and CD8+ T cells expressing CD26 in patients with type 1 diabetes. J Clin Immunol. 2011;31(6):977-984. doi:10.1007/s10875-011-9573-z

21. Klein BE, Klein R. Further insight on the limits of success of glycemic control in type1diabetes. Diabetes. 2015;64(2):341-343. doi:10.2337/db14-1447

22. Thabit H, Tauschmann M, Allen JM, et al. Home use of an artificial beta cell in type1diabetes. $N$ Engl $J$ Med. 2015;373(2129-40):44. doi:10.1056/NEJMoa1509351

23. Gorrell MD, Gysbers V, McCaughan GW. CD26: a multifunctional integral membrane and secreted protein of activated lymphocytes. Scand J Immunol. 2001;54(3):249-264. doi:10.1046/j.1365-3083. 2001.00984.x

24. Morimoto C, Schlossman SF. The structure and function of CD26 in the T-cell immune response. Immunol Res. 1998;161(1):55-70.

25. Abbott CA, Yu D, McCaughan GW, Gorrell MD. Post proline cleaving peptidases having DP. In: Jürgen L, Siegfried A, editors. Cellular Peptidases in Immune Functions and Diseases 2. Boston: Springer; 2002:103-109.

26. Barrett AJ, Woessner JF, Rawlings ND. Handbook of Proteolytic Enzymes. 3rd ed. Camb: Elsevier; 2012.

27. De Meester I, Korom S, Van Damme J, Scharpé S. CD26, let it cut or cut it down. Immunol Today. 1999;20(8):367-375. doi:10.1016/ S0167-5699(99)01486-3

28. Matteucci E, Giampietro O. Dipeptidyl peptidase-4 (CD26): knowing the function before inhibiting the enzyme. Curr Med Chem. 2009;16 (23):2943-2951. doi:10.2174/092986709788803114

29. Kieffer TJ, McIntosh $\mathrm{CH}$, Pederson RA. Degradation of glucose-dependent insulinotropic polypeptide and truncated glucagon-like peptide 1 in vitro and in vivo by dipeptidyl peptidase IV. Endocrinology. 1995;136(8):3585-3596. doi:10.1210/endo.136.8. 7628397

30. Drucker DJ. The biology of incretin hormones. Cell Metab. 2006;3 (3):153-165. doi:10.1016/j.cmet.2006.01.004

31. Hadjiyanni I, Siminovitch KA, Danska JS, Drucker DJ. Glucagon-like peptide-1 receptor signalling selectively regulates murine lymphocyte proliferation and maintenance of peripheral regulatory $\mathrm{T}$ cells. Diabetologia. 2010;53(4):730-740. doi:10.1007/s00125-009-1643-x

32. Baggio LL, Drucker DJ. Therapeutic approaches to preserve islet mass in type 2 diabetes. Annu Rev Med. 2006;57(1):265-281. doi:10.1146/annurev.med.57.110104.115624

33. Stone SF, Lee S, Keane NM, Price P, French MA. Association of increased hepatitis $\mathrm{C}$ virus (HCV)-specific IgG and soluble CD26 dipeptidyl peptidase IV enzyme activity with hepatotoxicity after highly active antiretroviral therapy in human immunodeficiency virus-HCV-coinfected patients. $J$ Infect Dis. 2002;186 (10):1498-1502. doi: $10.1086 / 344892$

34. Kobayashi H, Hosono O, Mimori T, et al. Reduction of serum soluble CD26/dipeptidyl peptidase IV enzyme activity and its correlation with disease activity in systemic lupus erythematosus. $J$ Rheumatol. 2002;29(9):1858-1866.

35. Schönermarck U, Csernok E, Trabandt A, Hansen H, Gross WL. Circulating cytokines and soluble CD23, CD26 and CD30 in ANCA-associated vasculitides. Clin Exp Rheumatol. 2000;18 (4):457-463.

36. Varga T, Somogyi A, Barna G, et al. Higher serum DPP-4 enzyme activity and decreased lymphocyte CD26 expression in type 1 diabetes. Pathol Oncol Res. 2011;17(4):925-930. doi:10.1007/s12 253-011-9404-9 
37. Osawa S, Kawamori D, Katakami N, et al. Significant elevation of serum dipeptidyl peptidase-4 activity in young-adult type 1 diabetes. Diabetes Res Clin Pract. 2016;113:135-142. doi:10.1016/j.diabres. 2015.12.022

38. Iwabuchi A, Kamoda T, Saito M, et al. Serum dipeptidyl peptidase 4 activity in children with type 1 diabetes mellitus. J Pediatr Endocrinol Metab. 2013;26(11-12):1093-1097. doi:10.1515/jpem-2013-0122

39. Duvnjak L, Blaslov K, Vučić Lovrenčić M, Knežević Ćuća J. Persons with latent autoimmune diabetes in adults express higher dipeptidyl peptidase-4 activity compared to persons with type 2 and type 1 diabetes. Diabetes Res Clin Pract. 2016;121:119-126. doi:10.1016/ j.diabres.2016.09.013

40. Ishibashi Y, Matsui T, Maeda S, Higashimoto Y, Yamagishi S-I. Advanced glycation end products evoke endothelial cell damage by stimulating soluble dipeptidyl peptidase-4 production and its interaction with mannose 6-phosphate/insulin-like growth factor II receptor. Cardiovasc Diabetol. 2013;12(1):125. doi:10.1186/1475-2840-12-125

41. Tahara N, Yamagishi SI, Takeuchi M, et al. Serum levels of advanced glycation end products (AGEs) are independently correlated with circulating levels of dipeptidyl peptidase-4 (DPP-4) in humans. Clin Biochem. 2013;46(4-5):300-303. doi:10.1016/j.clinbiochem.2012. 11.023

42. Yamagishi S, Fukami K, Matsui T. Crosstalk between advanced glycation end products (AGEs)-receptor RAGE axis and dipeptidyl peptidase-4-incretin system in diabetic vascular complications. Cardiovasc Diabetol. 2015;14(1):2. doi:10.1186/s12933-015-0176-5

43. Matsui T, Nishino Y, Takeuchi M, Yamagishi S. Vildagliptin blocks vascular injury in thoracic aorta of diabetic rats by suppressing advanced glycation end product-receptor axis. Pharmacol Res. 2011;63(5):383-388. doi:10.1016/j.phrs.2011.02.003

44. Matsui T, Nakashima S, Nishino Y, et al. Dipeptidyl peptidase-4 deficiency protects against experimental diabetic nephropathy partly by blocking the advanced glycation end products-receptor axis. Lab Invest. 2015;95(5):525-533. doi:10.1038/labinvest.2015.35

45. Ishibashi Y, Matsui T, Takeuchi M, Yamagishi S. Sitagliptin augments protective effects of GLP-1 against advanced glycation end product receptor axis in endothelial cells. Horm Metab Res. 2011;43 (10):731-734. doi:10.1055/s-0031-1284383

46. Terasaki M, Yashima H, Mori Y, et al. A dipeptidyl peptidase-4 inhibitor inhibits foam cell formation of macrophages in type 1 diabetes via suppression of CD36 and ACAT-1 expression. Int J Mol Sci. 2020;21(13):4811. doi:10.3390/ijms21134811

47. Pala L, Mannucci E, Pezzatini A, et al. Dipeptidyl peptidase-IV expression and activity in human glomerular endothelial cells. Biochem Biophys Res Commun. 2003;310(1):28-31. doi:10.1016/j. bbrc.2003.08.111

48. Miyazaki M, Kato M, Tanaka K, et al. Increased hepatic expression of dipeptidyl peptidase-4 in non-alcoholic fatty liver disease and its association with insulin resistance and glucose metabolism. Mol Med Rep. 2012;5(3):729-733. doi:10.3892/mmr.2011.707

49. Mosmann TR, Cherwinski H, Bond MW, Giedlin MA, Coffman RL. Two types of murine helper $\mathrm{T}$ cell clone. I. definition according to profiles of lymphokine activities and secreted proteins. J Immunol. 1986;136(7):2348-2357.

50. Proost P, Struyf S, Schols D, et al. Truncation of macrophage-derived chemokine by CD26/dipeptidyl-peptidase IV beyond its predicted cleavage site affects chemotactic activity and CC chemokine receptor 4 interaction. J Biol Chem. 1999;274(7):3988-3993. doi:10.1074/ jbc.274.7.3988

51. Willheim M, Ebner C, Baier K, et al. Cell surface characterization of $\mathrm{T}$ lymphocytes and allergen-specific $\mathrm{T}$ cell clones: correlation of CD26 expression with $\mathrm{T}(\mathrm{H} 1)$ subsets. J Allergy Clin Immunol. 1997;100(3):348-55H1. doi:10.1016/S0091-6749(97)70248-3

52. Yan S, Gessner R, Dietel C, Schmiedek U, Fan H. Enhanced ovalbumin-induced airway inflammation in CD26-/- mice. Eur J Immunol. 2012;42(2):533-540. doi:10.1002/eji.201041038
53. Rabinovitch A, Suarez-Pinzon WL, Sorensen O, Bleackley RC, Power RF. IFN-gamma gene expression in pancreatic islet-infiltrating mononuclear cells correlates with autoimmune diabetes in nonobese diabetic mice. J Immunol. 1995;154(9):4874-4882.

54. Sia C. Imbalance in Th cell polarization and its relevance in type 1 diabetes mellitus. Rev Diabet Stud. 2005;2(4):182-186. doi:10.1900/ RDS.2005.2.182

55. Karlsson Faresjö MGE, Ernerudh J, Ludvigsson J. Cytokine profile in children during the first 3 months after the diagnosis of type 1 diabetes. Scand J Immunol. 2004;59(5):517-526. doi:10.1111/ j.0300-9475.2004.01420.x

56. Karlsson MG, Lawesson SS, Ludvigsson J. Th1-like dominance in high-risk first-degree relatives of type I diabetic patients. Diabetologia. 2000;43(6):742-749. doi:10.1007/s001250051372

57. Hirai H, Kaino Y, Ito T, Kida K. Analysis of cytokine mRNA expression in pancreatic islets of nonobese diabetic mice. J Pediatr Endocrinol Metab. 2000;13(1):91-98. doi:10.1515/JPEM.2000.13.1.91

58. Klemann C, Schade J, Pabst R, et al. CD26/dipeptidyl peptidase 4deficiency alters thymic emigration patterns and leukcocyte subsets in F344-rats age-dependently. Clin Exp Immunol. 2009;155(2):357-365. doi:10.1111/j.1365-2249.2008.03839.x

59. Franco R, Valenzuela A, Lluis C, Blanco J. Enzymatic and extraenzymatic role of ecto-adenosine deaminase in lymphocytes. Immunol Rev. 1998;161(1):27-42. doi:10.1111/j.1600-065X.1998.tb01569.x

60. Dong RP, Kameoka J, Hegen M, et al. Characterization of adenosine deaminase binding to human CD26 on T cells and its biologic role in immune response. J Immunol. 1996;156(4):1349-1355.

61. Dong RP, Tachibana K, Hegen M, et al. Determination of adenosine deaminase binding domain on CD26 and its immunoregulatory effect on T cell activation. J Immunol. 1997;159(12):6070-6076.

62. Martín M, Huguet J, Centelles JJ, Franco R. Expression of ecto-adenosine deaminase and CD26 in human T cells triggered by the TCR-CD3 complex. Possible role of adenosine deaminase as costimulatory molecule. J Immunol. 1995;155(10):4630-4643.

63. Ohnuma K, Dang NH, Morimoto C. Revisiting an old acquaintance: CD26 and its molecular mechanisms in $\mathrm{T}$ cell function. Trends Immunol. 2008;29(6):295-301. doi:10.1016/j.it.2008.02.010

64. Liu Z, Christensson M, Forslöw A, De Meester I, Sundqvist KG. A CD26-controlled cell surface cascade for regulation of T cell motility and chemokine signals. $J$ Immunol. 2009;183(6):3616-3624. doi:10.4049/jimmunol.0804336

65. Reinhold D, Bank U, Bühling F, et al. Inhibitors of dipeptidyl peptidase IV induce secretion of transforming growth factor- $\beta 1$ in PWM-stimulated PBMC and T cells. Immunology. 1997;91 (3):354-360. doi:10.1046/j.1365-2567.1997.d01-2258.x

66. Sakaguchi S, Ono M, Setoguchi R, et al. Foxp3+ CD25+ CD4+ natural regulatory $\mathrm{T}$ cells in dominant self-tolerance and autoimmune disease. Immunol Res. 2006;212(1):8-27.

67. Zhang N, Schröppel B, Lal G, et al. Regulatory T cells sequentially migrate from inflamed tissues to draining lymph nodes to suppress the alloimmune response. Immunity. 2009;30(3):458-469. doi:10.10 16/j.immuni.2008.12.022

68. Brode S, Raine T, Zaccone P, Cooke A. Cyclophosphamide-induced type-1 diabetes in the NOD mouse is associated with a reduction of CD4+ CD25+ Foxp3+ regulatory T cells. J Immunol. 2006;177 (10):6603-6612. doi:10.4049/jimmunol.177.10.6603

69. Tian B, Hao J, Zhang Y, et al. Upregulating CD4+ CD25+ FOXP3+ regulatory $\mathrm{T}$ cells in pancreatic lymph nodes in diabetic NOD mice by adjuvant immunotherapy. Transplantation. 2009;87(2):198-206. doi:10.1097/TP.0b013e3181933261

70. Morran MP, Omenn GS, Pietropaolo M. Immunology and genetics of type 1 diabetes. Mt Sinai J Med. 2008;75(4):314-327. doi:10.1002/msj.20052

71. Zhao Y, Yang L, Wang X, Zhou Z. The new insights from DPP-4 inhibitors: their potential immune modulatory function in autoimmune diabetes. Diabetes Metab Res Rev. 2014;30(8):646-653. doi:10.1002/dmrr.2530 
72. Kim YG, Min SH, Hahn S, Oh TJ, Park KS, Cho YM. Efficacy and safety of the addition of a dipeptidyl peptidase- 4 inhibitor to insulin therapy in patients with type 2 diabetes: a systematic review and meta-analysis. Diabetes Res Clin Pract. 2016;116:86-95. doi:10.1016/j.diabres.2016.03.011

73. Davanso MR, Caliari-Oliveira C, Couri CEB, et al. DPP-4 inhibition leads to decreased pancreatic inflammatory profile and increased frequency of regulatory $\mathrm{T}$ cells in experimental type 1 diabetes. Inflammation. 2019;42(2):449-462. doi:10.1007/s10753-018-00954-3

74. Pinheiro MM, Pinheiro FM, Torres MA. Four-year clinical remission of type 1 diabetes mellitus in two patients treated with sitagliptin and vitamin D3. Endocrinol Diabetes Metab Case Rep. 2016;2016:16-0099. doi:10.1530/EDM-16-0099

75. Lima-Martínez MM, Guerra-Alcalá E, Contreras M, Nastasi J, Noble JA, Polychronakos C. One year remission of type 1 diabetes mellitus in a patient treated with sitagliptin. Endocrinol Diabetes Metab Case Rep. 2014;2014:140072. doi:10.1530/EDM-14-0072

76. Couri CE, Oliveira MC, Stracieri AB, et al. C-peptide levels and insulin independence following autologous nonmyeloablative hematopoietic stem cell transplantation in newly diagnosed type 1 diabetes mellitus. JAMA. 2009;301(15):1573-1579. doi:10.1001/jama.2009.470

77. Hari Kumar KV, Shaikh A, Prusty P. Addition of exenatide or sitagliptin to insulin in new onset type 1 diabetes: a randomized, open label study. Diabetes Res Clin Pract. 2013;100(2):e55-8. doi:10.1016/j.diabres.2013.01.020

78. Ellis SL, Moser EG, Snell-Bergeon JK, Rodionova AS, Hazenfield RM, Garg SK. Effect of sitagliptin on glucose control in adult patients with type 1 diabetes: a pilot, double-blind, randomized, crossover trial. Diabetes Med. 2011;28(10):1176-1181. doi:10.1111/ j.1464-5491.2011.03331.x

79. Guo H, Fang C, Huang Y, Pei Y, Chen L, Hu J. The efficacy and safety of DPP4 inhibitors in patients with type 1 diabetes: a systematic review and meta-analysis. Diabetes Res Clin Pract. 2016;121:184-191. doi:10.1016/j.diabres.2016.08.022

80. Wang Q, Long M, Qu H, et al. DPP-4 inhibitors as treatments for type 1 diabetes mellitus: a systematic review and meta-analysis. J Diabetes Res. 2018;2018:1-10. doi:10.1155/2018/5308582

81. Johansen O, Boehm B, Grill V, Torjesen P, Bhattacharya S, Patel S. Beta-cell function in latent autoimmune diabetes in adults treated with linagliptin vs glimepiride: exploratory results from a 2-year double-blind randomized controlled study. Endocr Rev. 2012;33(4): SUN-LB1.

82. Nathan DM, Genuth S, Lachin J, Cleary P, Crofford O, Diabetes Control and Complications Trial Research Group. The effect of intensive treatment of diabetes on the development and progression of long-term complications in insulin-dependent diabetes mellitus. N Engl J Med. 1993;329(14):977-986.
83. Elashoff M, Matveyenko AV, Gier B, Elashoff R, Butler PC. Pancreatitis, pancreatic, and thyroid cancer with glucagon-like peptide-1-based therapies. Gastroenterology. 2011;141(1):150-156. doi:10.1053/j.gastro.2011.02.018

84. Faillie JL, Azoulay L, Patenaude V, Hillaire-Buys D, Suissa S. Incretin based drugs and risk of acute pancreatitis in patients with type 2 diabetes: cohort study. BMJ. 2014;348(apr24 1):g2780. doi:10.1136/bmj.g2780

85. Nakamura T, Ito T, Uchida M, et al. PSCs and GLP-1R: occurrence in normal pancreas, acute/chronic pancreatitis and effect of their activation by a GLP-1R agonist. Lab Invest. 2014;94(1):63-78. doi:10.1038/labinvest.2013.133

86. Butler PC, Elashoff M, Elashoff R, Gale EA. A critical analysis of the clinical use of incretin-based therapies: are the GLP-1 therapies safe? Diabetes Care. 2013;36(7):2118-2125. doi:10.2337/dc12-2713

87. Gier B, Matveyenko AV, Kirakossian D, Dawson D, Dry SM, Butler PC. Chronic GLP-1 receptor activation by exendin-4 induces expansion of pancreatic duct glands in rats and accelerates formation of dysplastic lesions and chronic pancreatitis in the $\operatorname{Kras}(\mathrm{G} 12 \mathrm{D})$ mouse model. Diabetes. 2012;61(5):1250-1262. doi:10.2337/db11-1109

88. Dicembrini I, Montereggi C, Nreu B, Mannucci E, Monami M. Pancreatitis and pancreatic cancer in patientes treated with dipeptidyl peptidase-4 inhibitors: an extensive and updated meta-analysis of randomized controlled trials. Diabetes Res Clin Pract. 2020;159:107981. doi:10.1016/j.diabres.2019.107981

89. White WB, Cannon CP, Heller SR, et al. Alogliptin after acute coronary syndrome in patients with type 2 diabetes. $N$ Engl J Med. 2013;369(14):1327-1335. doi:10.1056/NEJMoa1305889

90. Scirica BM, Bhatt DL, Braunwald E, et al. Saxagliptin and cardiovascular outcomes in patients with type 2 diabetes mellitus. $N$ Engl $J$ Med. 2013;369(14):1317-1326. doi:10.1056/NEJMoa1307684

91. Tricco AC, Antony J, Khan PA, et al. Safety and effectiveness of dipeptidyl peptidase-4 inhibitors versus intermediate-acting insulin or placebo for patients with type 2 diabetes failing two oral antihyperglycaemic agents: a systematic review and network meta-analysis. BMJ Open. 2014;4(12):e005752. doi:10.1136/bmjopen-2014-005752

92. Monami M, Dicembrini I, Martelli D, Mannucci E. Safety of dipeptidyl peptidase-4 inhibitors: a meta-analysis of randomized clinical trials. Curr Med Res Opin. 2011;27(Suppl 3):57-64. doi:10.1185/ 03007995.2011.602964

\section{Publish your work in this journal}

Diabetes, Metabolic Syndrome and Obesity: Targets and Therapy is an international, peer-reviewed open-access journal committed to the rapid publication of the latest laboratory and clinical findings in the fields of diabetes, metabolic syndrome and obesity research. Original research, review, case reports, hypothesis formation, expert opinion and commentaries are all considered for publication. The manuscript management system is completely online and includes a very quick and fair peer-review system, which is all easy to use. Visit http://www.dovepress.com/testimonials.php to read real quotes from published authors. 